\author{
SK Datta ${ }^{1}$,KK Sethi ${ }^{1}$, S Singh $^{2 \star}$ and M \\ Fotedar ${ }^{2}$ \\ ${ }^{1}$ Department of Cardiology, Delhi heart and lung \\ institute, New Delhi, India \\ ${ }^{2}$ Department of Non-invasive Cardiology, Delhi \\ heart and lung institute, New Delhi, India \\ Dates: Received: 14 June, 2016; Accepted: 29 July, \\ 2016; Published: 01 August, 2016 \\ ${ }^{*}$ Corresponding author: Sukhvinder Singh, \\ Department of Non-invasive Cardiology, Delhi heart \\ and lung institute, New Delhi, India, Tel: 9717205832 ; \\ +911147098698; E-mail: kuks145@yahoo.co.in \\ www.peertechz.com

\section{Case Report \\ Complete Percutaneous Management of Lutembacher Syndrome with Severe Pulmonary Hypertension in a Middle Aged Indian Female: Is this the Magic Wand?}

ISSN: 2455-5282

Keywords: Lutembacher syndrome; Percutanoeus management; Mitral stenosis; Atrial septal defect; PTMC; Device closure

\section{Abbrevations}

ASD: Atrial Septal Defect; ECG: Electrocardiogram; PTMC: Percutaneous Transmitral Commissurotomy

\section{Introduction}

Lutembacher syndrome is a combination of ostium secundum atrial septal defect with acquired rheumatic mitral stenosis. The management of lutembacher syndrome was only surgical till 1990s. Total percutaneous management has been described in late 1990s. Percutaneous management is relatively cheaper option and saves the patient from artificial valve and related complications. However, only a small number of cases of total percutaneous management of this condition are available in world literature.

\section{Case Presentation}

A fifty-five years old female was referred to our institute from a remote place for double valve replacement (aortic and mitral) with atrial septal defect closure. She had a history of breathlessness on exertion for one year that had progressively increased from class II to class IV. The clinical examination revealed a low grade mid diastolic rumble and loud pulmonary component of second heart sound. A mid systolic murmur was present at left upper parasternal region and a pansystolic murmur was present at left lower parasternal region. The ECG showed normal sinus rhythm with left atrial abnormality. Echocardiogram revealed rheumatic heart disease with very severe mitral stenosis with mitral valve area of $0.7 \mathrm{~cm}^{2}\left(0.598 \mathrm{~cm}^{2} / \mathrm{m}^{2}\right.$ of body surface area) (Figure 1, Video 1). There was trace mitral regurgitation and Wilkin's score was $7 / 16$. Patient also had moderate tricuspid regurgitation and severe pulmonary hypertension with calculated right ventricular systolic pressure of $93 \mathrm{mmHg}$ (Figure 2). Patient had an ostium secundum atrial septal defect (ASD) of size $8 \mathrm{~mm}$ with left to right shunt (Video 2). She had right atrial, left atrial as well as right ventricular enlargement. Not surprisingly, the mean gradient across the mitral valve was only $6.3 \mathrm{mmHg}$ (Figure 3 ). There was associated aortic valve disease in the form of mild aortic stenosis and mild aortic regurgitation.

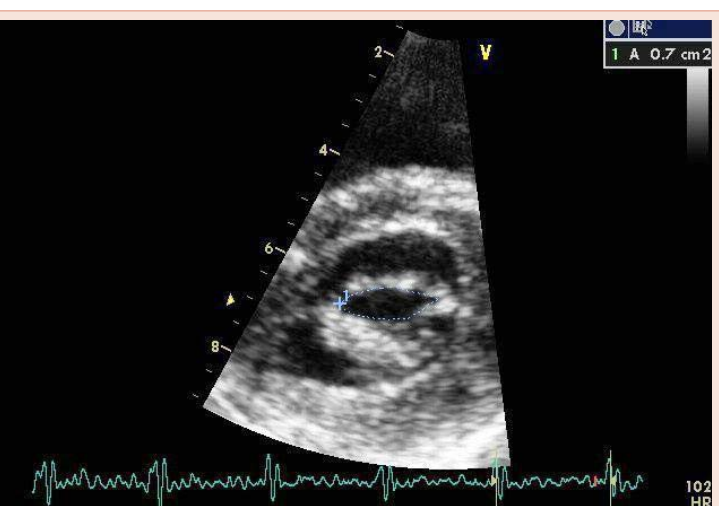

Figure 1: Parasternal short axis view of echocardiogram showing mitral valve area of $0.7 \mathrm{~cm}^{2}$ by planimetry. 
Patient was subjected to transesophageal echocardiogram which revealed the atrial septal defect size to be $\sim 14 \mathrm{~mm}$ with adequate margins (Figure 4 ). Catheter coronary angiogram was also performed which showed normal coronary arteries with right dominance.

Patient was planned for a sequential percutaneous transmitral commissurotomy (PTMC) followed by device closure of atrial septal defect after assessment of pulmonary hypertension.

Patient's baseline hemodynamics revealed left atrial pressure of $28 / 4 \mathrm{mmHg}$ and peak right ventricular systolic pressure of $85 \mathrm{mmHg}$.

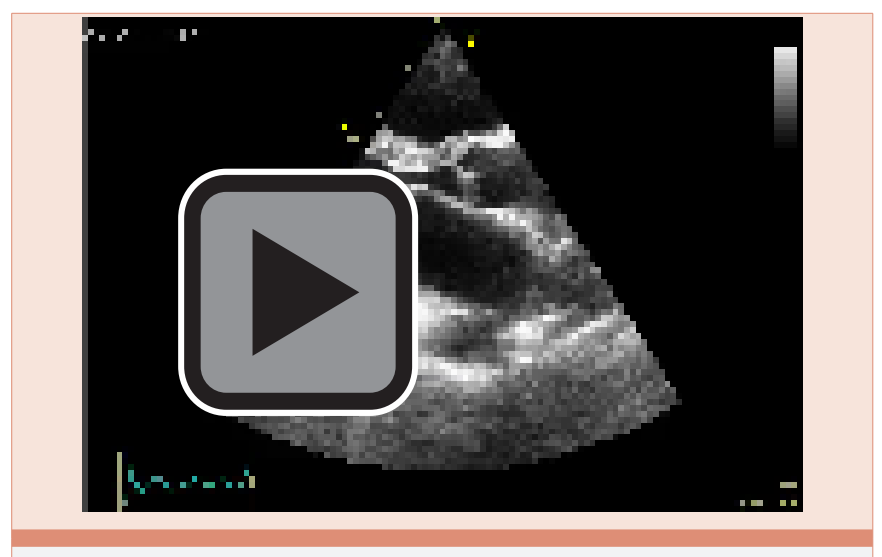

Video 1:

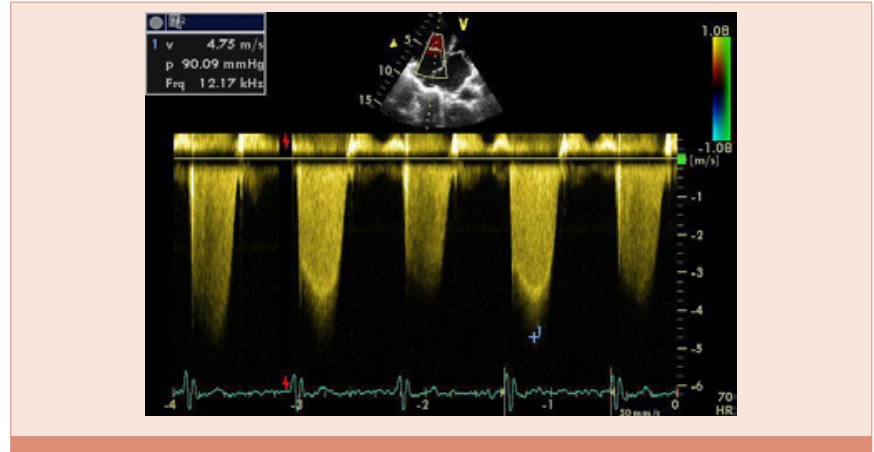

Figure 2: Echocardiogram showing Doppler of tricuspid regurgitation jet with gradient of $90 \mathrm{mmHg}$.

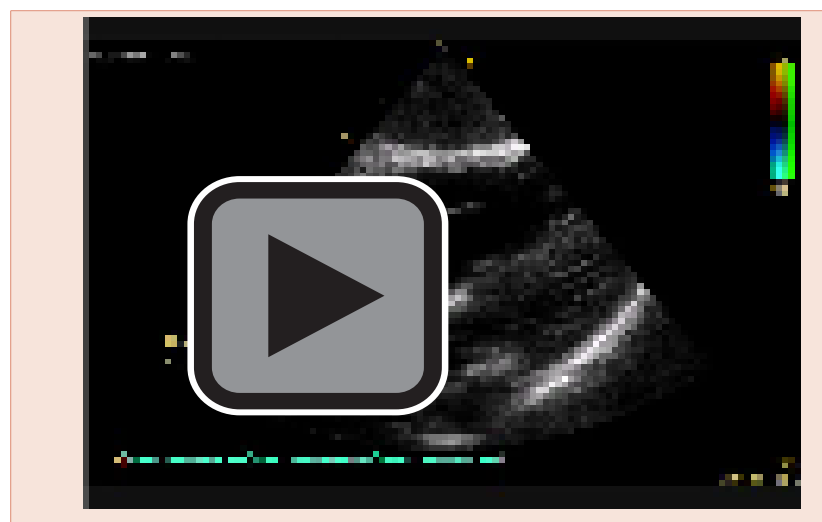

Video 2:

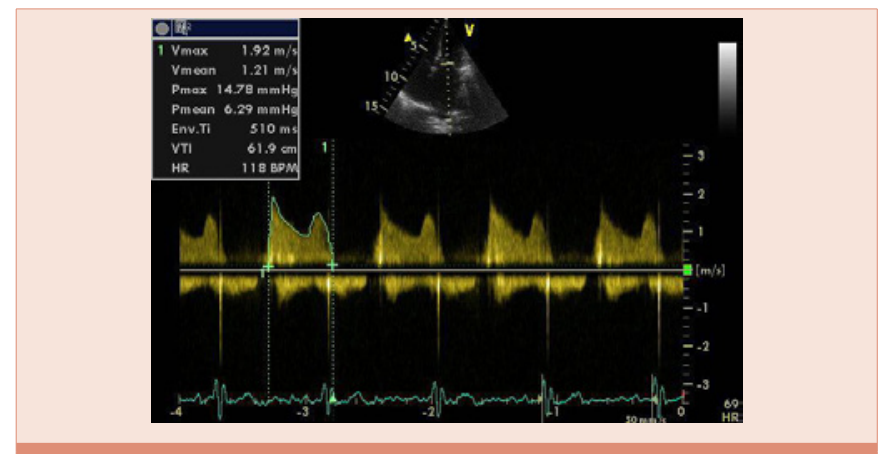

Figure 3: Echocardiogram showing Doppler of mitral valve with mean gradient of $6.29 \mathrm{mmHg}$.

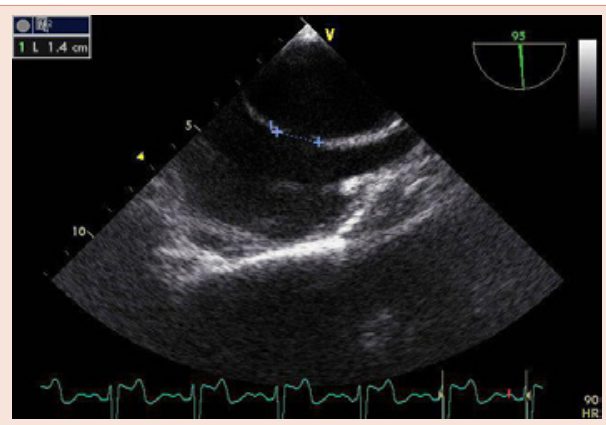

Figure 4: Transesophageal echocardiogram showing an ostium secundum atrial spetal defect of $14 \mathrm{~mm}$.

Presence of atrial septal defect was confirmed. PTMC was performed using $25 \mathrm{~mm}$ inoue balloon (Video 3). Immediately after PTMC, the right ventricular systolic pressure reduced to $60 \mathrm{mmHg}$. Trace mitral regurgitation was present on contrast left ventriculography. The ASD was closed using $18 \mathrm{~mm}$ device (Lifetech, Heart R) (Video 4). Post ASD closure the right ventricular pressure decreased further to 40 $\mathrm{mmHg}$. There was no shunt across the atrial septum on contrast study. Procedure remained uneventful.

Patient underwent another echocardiogram after 48 hours of the procedure. It revealed absence of any residual shunt across the interatrial septum. The mitral valve area by planimetry increased to $1.3 \mathrm{~cm}^{2}\left(1.1 \mathrm{~cm}^{2} / \mathrm{m}^{2}\right.$ of body surface area) (Figure 5, Videos 5,6). Mean gradient across the mitral valve reduced to $2.3 \mathrm{~cm}^{2}$ (Figure 6). The calculated right ventricular systolic pressure dropped to 32 $\mathrm{mmHg}$ (Figure 7). There was trace mitral regurgitation. The ASD closure device was seen in normal position (Video 7). Patient was symptomatically much better on her first post-procedure visit.

\section{Discussion}

Lutembacher syndrome was first described by a French physician in 1916. It is currently regarded as a combination of congenital ostium secundum atrial septal defect and acquired mitral stenosis although Lutembacher stressed that his patient was having a congenital mitral stenosis [1]. The natural history of mitral stenosis changes favourably by presence of ASD which allows left atrium to decompress and prevents development of symptoms for long as gradient across the 


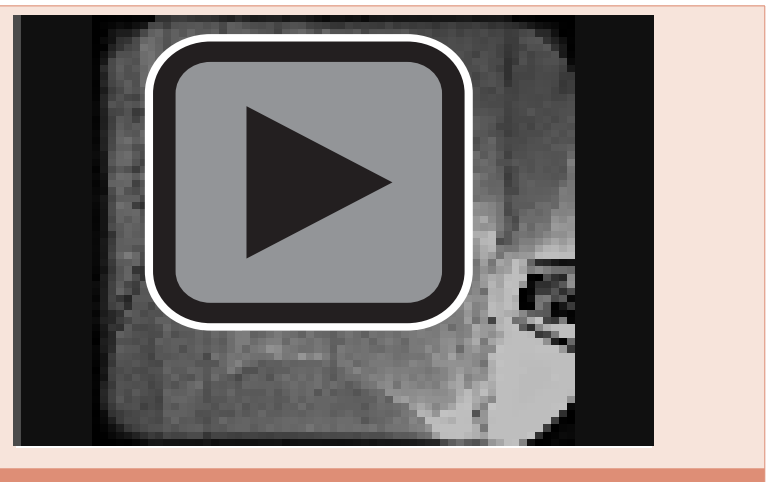

Video 3:

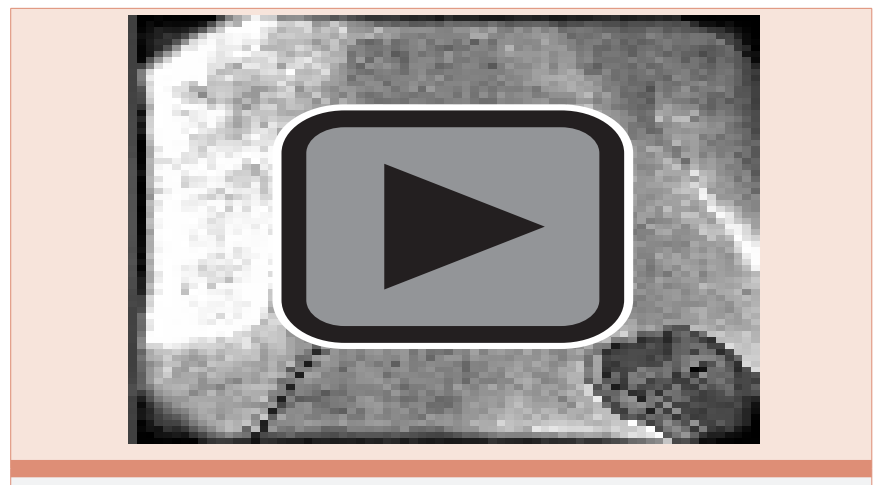

Video 4:

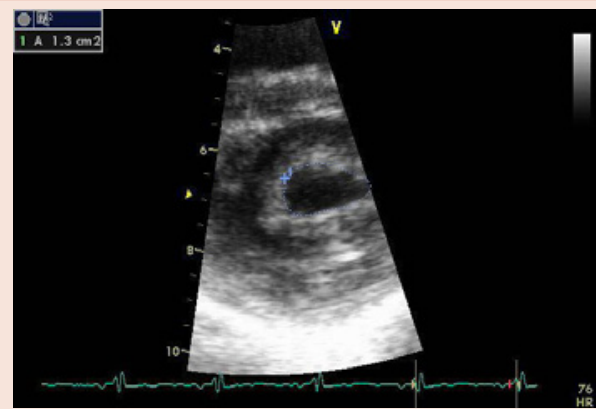

Figure 5: Parasternal short axis view of echocardiogram showing mitral valve area of $1.3 \mathrm{~cm}^{2}$ by planimetry after percutaneous commissurotomy.

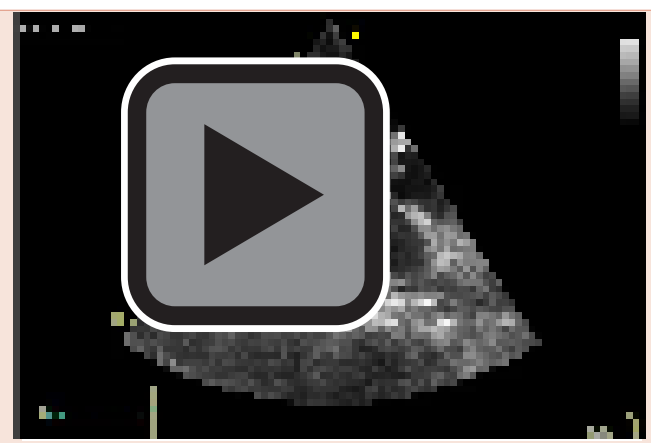

Video 5:

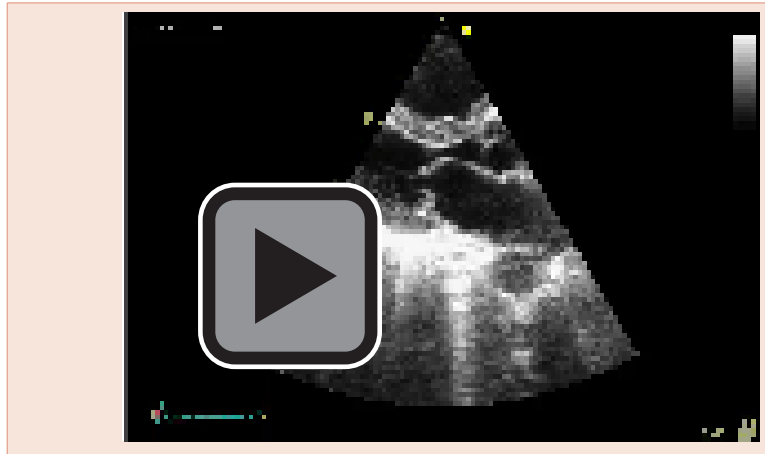

Video 6:

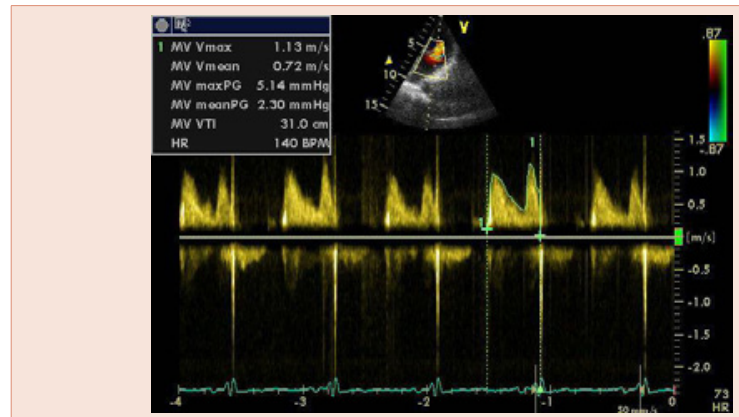

Figure 6: Echocardiogram showing Doppler of mitral valve with mean gradient of $2.3 \mathrm{mmHg}$ after percutaneous commissurotomy.

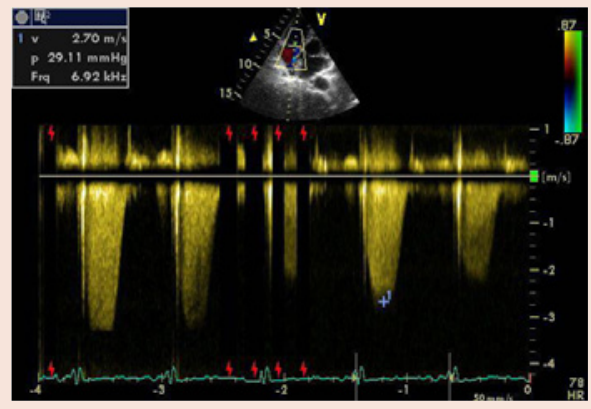

Figure 7: Echocardiogram showing Doppler of tricuspid regurgitation jet with gradient of $29 \mathrm{mmHg}$ after percutaneous commissurotomy.

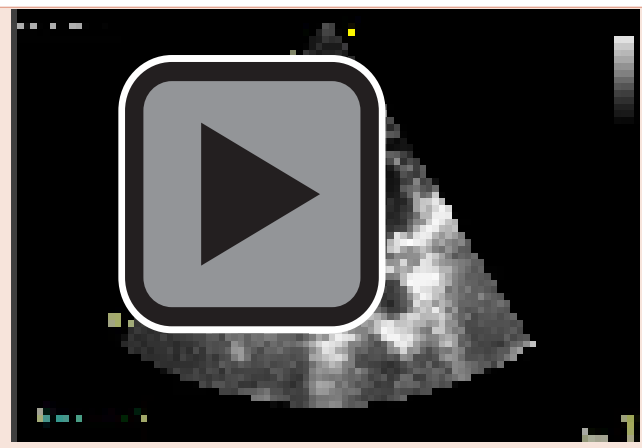

Video 7:

Citation: Datta SK, Sethi KK, Singh S, Fotedar M (2016) Complete Percutaneous Management of Lutembacher Syndrome with Severe Pulmonary 
mitral valve decreases. The pressure half time method and gradients across the mitral valve underestimate the severity of mitral stenosis in such a scenario. The mitral valve area should be measured by planimetry and continuity equation in these cases [2]. On the other hand, the excessive blood flow from left to right atrium leads to volume overload of right atrium and right ventricle leading to atrial arrhythmias and right sided failure. Thus mitral stenosis worsens the hemodynamic of ASD [1].

The treatment of lutembacher syndrome was surgical only until recently. Ruiz in 1992 reported first successful percutaneous management of lutembacher syndrome. They also performed balloon valvotomy of aortic valve on the same sitting [3]. The experience of percutaneous management of this condition has remained restricted to case reports only and large scale comparative studies have not been published as yet [4]. However, it is a promising and economically viable option for patients of poorer countries where rheumatic fever is more prevalent.

\section{References}

1. Perloff JK (2003) From Atrial septal defect. In: The clinical recognition of congenital heart disease, 5th edition. Edited by JK Perloff WB Saunders, Philadelphia 233-299.

2. Vasan RS, Shrivastava S, Kumar MV (1992) Value and limitations of Doppler echocardiographic determination of mitral valve area in Lutembacher syndrome. J Am Coll Cardiol 20: 1362-1370.

3. Ruiz CE, Gamra H, Mahrer P, Allen JW, O'Laughlin MP, et.al. (1992) Percutaneous closure of a secundum atrial septal defect and double balloon valvotomies of a severe mitral and aortic valve stenosis in a patient with Lutembacher's syndrome and severe pulmonary hypertension. Cathet Cardiovasc Diagn 25:309-312.

4. Babu MB, Rajasekhar D, Vanajakshamma V (2004) Percutaneous transcatheter treatment of Lutembacher syndrome. J NTR Univ Health Sci 3: $180-182$. 